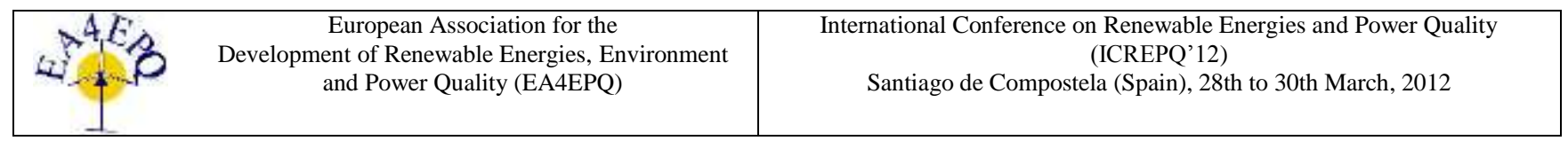

\title{
Advanced Universal Power Quality Conditioning Systems for Stabilizing Micro-Grid's Frequency
}

\author{
B. Rahmani ${ }^{1}$ and M. Tavakoli Bina ${ }^{1}$ \\ ${ }^{1}$ Faculty of Electrical Engineering \\ K. N. Toosi University of Technology, Tehran, Iran. \\ E-mails: Rahmani.pwr@ee.kntu.ac.ir,Tavakoli_bina@ieee.org
}

\begin{abstract}
This paper proposes a new unified active filter to alleviate instantaneous unwanted oscillating powers as they may lead to frequency variations in weak systems. First, the paper presents negative impacts of capacitive loads on the shunt active power filter performance in compensation of instantaneous oscillating real power. Secondly, an advanced universal power quality conditioning system (AUPQS) for three-phase/four-wire systems under non-ideal waveforms is introduced. By considering the suggested compensation algorithm, the AUPQS is able to extremely suppress instantaneous oscillating powers caused by distorted-unbalanced load-terminal voltages. Moreover, an independent single-phase converter is suggested at the load-end in order to regulate the DC-link voltage. Therefore, the instantaneous oscillating powers perfectly suppress and thus, the source-end three-phase currents will be purely sinusoidal. The suggested AUPQS is used to stabilize micro grid frequency. The effectiveness and flexibility of the proposed AUPQS are confirmed by Matlab/ Simulink simulations.
\end{abstract}

Key words: AUPQS, DC-link, Load-Terminal Voltage, Unified Power Quality Conditioning System.

\section{Introduction}

Rapid growth of power electronics loads brings about lots of power quality problems such as harmonics, unbalance operation and excessive source-end neutral current in three-phase supplying networks. These power quality problems cause many adverse effects like errors in measuring instruments, accentuation of harmonics, false operation of circuit breakers and relays, reduction in transmission system efficiency, malfunction in electronic equipment and overheating of transformers [1]. A common compensation algorithm is the optimal solution (OS) [2]-[3]. The OS is simple to implement, applicable only to three-wire balanced systems. Further, the generalized theory of instantaneous power (GTIP) definitions were proposed [4]. It is shown in [5]-[6] that the GTIP can be derived from the OS. Although the compensation algorithm based on the GTIP has an acceptable performance in three-phase four-wire balanced systems, distorted source-end zero sequence current is unavoidable under non-ideal waveforms [7]. Other prominent proposed power theories are Fryze, Buchholz and Depenbrock (FBD) [8], current's physical component
(CPC) [9] (in the frequency domain interprets and describes power phenomena in three-phase three-wire systems), conservative power theory (CPT) [10]and the $p$ $q-r$ theory [11]-[13] (defined in $\alpha-\beta-0$ reference frame). The control algorithms based on these power theories provide unsatisfactory outcomes when the load-terminal voltages are unbalanced and distorted [6]. In [7], advanced GTIP (A-GTIP) theory was proposed as a solution to provide accurately reference signals for the active power filters. It has been shown that the A-GTIP theory is appropriate for any three-phase/four-wire circuit conditions.

Based on the requirements, an activating algorithm and a formation need to be chosen properly providing wide ranges of objectives either individually or in combination. In [14], shunt active power filter (SAPF) is introduced to eliminate power oscillations. It argues that shunt active filters even under the compensation algorithm based on A-GTIP, produce unacceptable performance in the presence of capacitive loads (with very low $\mathrm{Z}_{\mathrm{L}}$ ). Some modern solutions in the form of unified power quality controller (UPQC) and universal power quality conditioning systems (UPQS) were proposed for fully power compensation in three-wire networks [15], [16]. The compensation algorithms of the shunt part of these unified active filters are resulting in unsatisfactory outcomes when the load-terminal voltages are unbalanced and distorted [7], [17], [18]. This paper intends to perform vital corrections on the shunt filter activating algorithm for the aforementioned unified power compensators for a satisfactory power compensation and harmonics alleviation especially in three-phase/four-wire systems. The paper is proposed an AUPQS which leads to purely sinusoidal source-end currents under both distortedunbalanced load-terminal voltages and capacitive load conditions. Moreover, the isolated DC-link voltage regulating converter is connected to just one-phase at the load-terminal side, therefore, unlike the previous proposal of having three-phase converter at the source-end, the new suggestion will be able to regulate the DC-link without any distortion. At the end, the proposed unified 
compensator is applied to a micro-grid. In a micro-grid, frequency variation may appear due to the oscillation in the load or oscillation in the renewable energy sources like wind power [19]. Micro-grids mainly have torsional torque vibration that could be damped by active filters to avoid frequency variation [14], [20].

The paper is organized as follows. In section II, the structure of general unified compensators is presented. Then, by introducing a compensation algorithm based on advanced generalized theory of instantaneous power (AGTIP), the AUPQS is proposed in three-phase/four-wire systems in section III. Further, an AUPQS is suggested for three-phase four-wire systems. Finally, simulations verify performance of the AUPQS in line with the desirable outcomes.

\section{The structure of general unified controller}

Basic structure of common unified active filters consist of the combination of shunt-active and series-active filters.

2.1 Shunt filter: the SAPF is used to eliminate loadterminal current harmonics and leads to highly pure sinusoidal source-end currents. The generalized theory of instantaneous power definition (GTIP) is usually used to provide reference signals in control schemes of the SAPFs.

\section{Shunt active filter malfunctioning}

$A$. Let us suppose that source voltage $(\mathrm{v}(\mathrm{t}))$ involves all sequences $\left(\mathrm{v}(t)=\mathrm{v}+(t)+\mathrm{v}-(t)+\mathrm{v}^{0}(t)\right.$, where $\mathrm{v}+(t), \mathrm{v}^{-}(t)$ and $\mathrm{v}^{0}(t)$ are positive, negative and zero sequence components of $\mathrm{v}(t)$, respectively). Therefore, the sourceend currents, using the OS $[2,3]$ can be rewritten as:

$$
\left\{\begin{array}{c}
i_{s}(t)=i_{s}^{+}(t)+i_{s}^{-}(t)+i_{s}^{0}(t)=\lambda \cdot v^{+}(t)+\lambda \cdot v^{-}(t)+\lambda \cdot v^{0}(t) \\
\lambda=\frac{\bar{P}(t)}{V(t) \cdot V(t)} \\
i_{c}(t)=i(t)-\frac{\bar{P}(t)}{V(t) \cdot V(t)} V(t)
\end{array}\right.
$$

Since the non-sinusoidal term $\mathrm{V}(\mathrm{t})$ in (1) acts as a source of distortion, the SAPF compensation algorithm will inject a distorted current. Therefore, the compensation algorithm derived from the GTIP under both asymmetric and distorted three-phase load-terminal voltages provides unacceptable outcomes. The A-GTIP theory takes (1) one step forward to overcome the stated issue by replacing $\mathrm{V}(t)$ with $\mathrm{V}^{+}(t)$ in (1) as follows:

$$
i_{s}(t)=\frac{\bar{P}^{+}(t)}{V^{+}(t) \cdot V^{+}(t)} V^{+}(t)
$$

As long as $\mathrm{V}^{+}(\mathrm{t})$ is the fundamental component of $\mathrm{V}(\mathrm{t})$, the source-end currents remain purely sinusoidal. Otherwise, the non-sinusoidal $\mathrm{V}^{+}(\mathrm{t})$ would generate distortions [6]; therefore, the SAPF compensation algorithm will inject a distorted current. The block diagram of the A-GTIP is shown in Fig. 1.

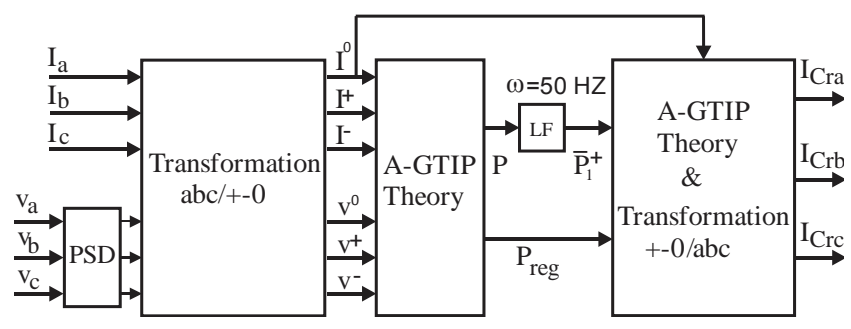

Figure 1: The A-GTIP algorithm stated in [7].

Unlike the previous proposition of shunt filters, compensation algorithm based on the A-GTIP theory for controlling the active compensator, result in eliminating all the distorted-unbalanced load-terminal voltages.

$B$. The SAPF produces controlled current in order to compensate harmonic and unbalanced currents drawn by the non-linear loads. The principles of shunt current injection can be explained base on fig. 2 .

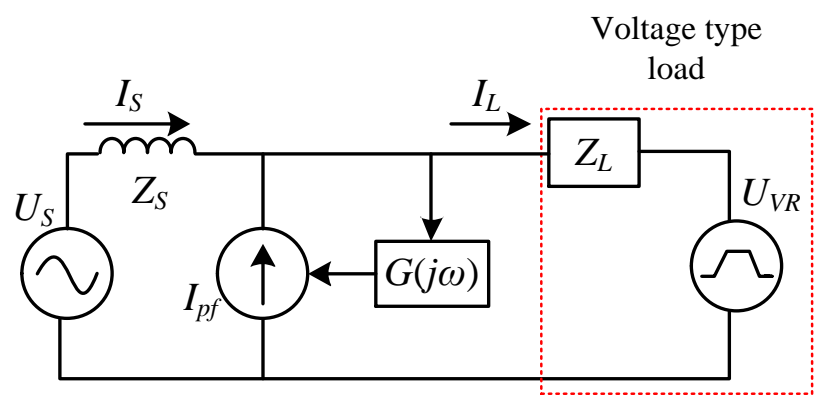

Figure 2: Compensation issue related to shunt active filter under voltage type capacitive loads.

Considering Fig. 2, if the injected current by the shunt filter $\left(I_{p f}\right)$ compensates the load harmonics, then it is expected to have pure sinusoidal source-end currents. Hence, arranging a KCL at the load terminal as well as a KVL within the available loop will lead to:

$$
\left\{\begin{array}{c}
I_{s}=(1-G(j \omega)) I_{L} \\
U_{s}=Z_{s} I_{s}+Z_{L}\left(I_{s}+G(j \omega) I_{L}\right)+U_{V R}
\end{array}\right.
$$

Where $G(j \omega)$ is the transfer function relating $\mathrm{I}_{\mathrm{L}}$ to $\mathrm{I}_{\mathrm{pf}}$. If for $\omega=\omega_{h}$, then $\left.\left.\left.\frac{Z_{L}(j \omega)}{1-G(j \omega)}\right|_{\omega=\omega_{h}}\right\rangle\right\rangle Z_{s}\left(\left.j \omega\right|_{\omega=\omega_{h}}\right)$; the load current $I_{L}(t)$ and the source-end current $I_{S}(t)$ are obtained as follows:

$$
\left\{\begin{array}{l}
I_{L}(j \omega)\left(\omega=\omega_{h}\right) \approx \frac{U_{s}(j \omega)-U_{V R}(j \omega)}{Z_{L}(j \omega)} \\
I_{s}(j \omega)\left(\omega=\omega_{h}\right)=\frac{U_{s}(j \omega)-U_{V R}(j \omega)}{Z_{S}(j \omega)+\frac{Z_{L}(j \omega)}{0}} \approx 0
\end{array}\right.
$$

When the load-terminal supplies single-phase and threephase diode rectifiers that charge therir assigned capacitances, the AC load-terminal sees effectively a very low $\mathrm{Z}_{\mathrm{L}}$; thus, even in the presence of the A-GTIP compensation algorithm (4) would not be fulfilled. Therefore, the shunt active filters cannot produce satisfactory outcomes. One solution could be inclusion of an series filter (SF) as follows. 
2.2 Series Filter: An active SF is used as a solution to remove the effects of source asymmetric and distorted voltage on the SAPF accuracy; Meanwhile, it forces capacitive load type harmonics to flow into the shunt filter. In fact the SF highly impede against frequency components in order to compensate harmonic currents drawn in the case of capacitive loaded diode rectifiers as shown in fig. 3 .

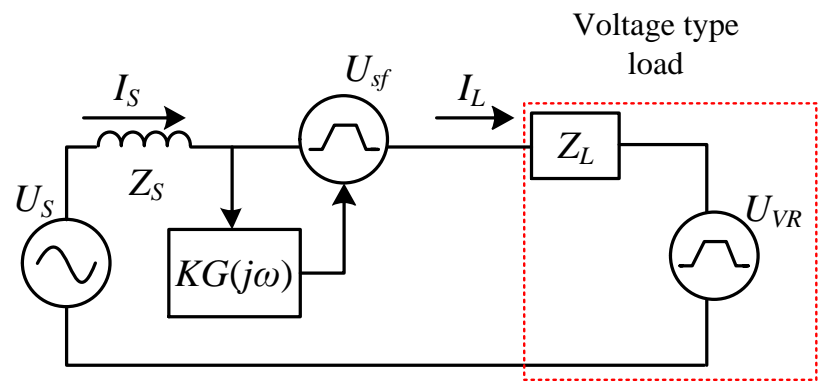

Figure 3: The SF provides an impedance to affect $\mathrm{Z}_{\mathrm{L}}$ of the voltage type capacitive load.

$$
\left\{\begin{array}{c}
U_{S f}(j \omega)=K G(j w) I_{S}(j \omega), G(j \omega)= \begin{cases}0, & \omega=\omega_{1} \\
1, & \omega=\omega_{\mathrm{h}}\end{cases} \\
I_{S}(j \omega)=\frac{U_{S}(j \omega)-U_{V R}(j \omega)}{Z_{S}(j \omega)+Z_{L}(j \omega)+K G(j \omega)}
\end{array}\right.
$$

In equation (5) $K$ is the impedance gain; if $K G(j \omega)\rangle>Z_{s}(j \omega)+\left.Z_{L}(j \omega)\right|_{\omega=\omega_{h}}$, then it can be shown that the source current tends zero at unwanted frequencies:

$$
\left\{\begin{array}{c}
I_{S}(j \omega)\left(\omega=\omega_{h}\right)=\frac{U_{S}(j \omega)-U_{V R}(j \omega)}{Z_{S}(j \omega)+Z_{L}(j \omega)+K G(j \omega)} \approx 0 \\
U_{S f}(j \omega)\left(\omega=\omega_{h}\right) \approx Z_{L}(j \omega) I_{L}(j \omega)+U_{S}(j \omega)
\end{array}\right.
$$

Figure 4 introduces an improved control algorithm for series active filter suitable for simulation and design purposes.

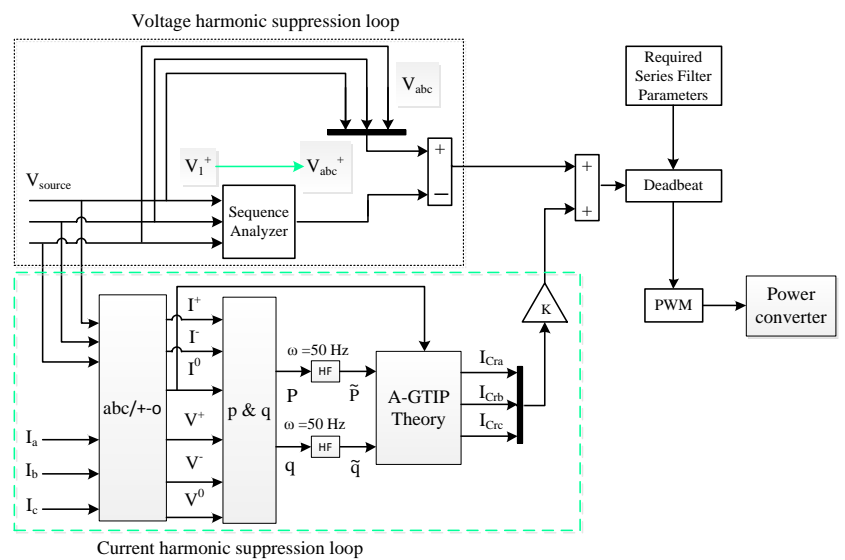

Figure 4: The suggested control algorithm for the SF, replacing fundamental current with fundamental voltage.

Fundamental component of the source voltage is measured in the harmonic voltage suppression loop to get the voltage deficiencies. The source-end current harmonics are obtained in the harmonic current suppression loop by spliting up both the instantaneous oscillating active and non-active power using the measured source-end currents.
The equivalent source harmonic current is then multiplied by $K$ to get the output voltage of the converter. Further, combination of unified shunt and series active filter produces such references that unwanted frequency components are attenuated according their harmonic order, leading to better currents at the source-end closer to sinusoidal waveforms (see (7) for $I_{s}$ ).

$$
\left\{\begin{array}{c}
\mathrm{I}_{\mathrm{L}}(j \omega)\left(\omega=\omega_{h}\right)=\frac{\mathrm{U}_{\mathrm{s}}(j \omega)-\mathrm{U}_{\mathrm{VR}}(j \omega)}{\mathrm{Z}_{\mathrm{L}}(j \omega)} \\
I_{s}(j \omega)\left(\omega=\omega_{h}\right)=\frac{U_{s}(j \omega)-U_{V R}(j \omega)}{Z_{S}(j \omega)+K G(j \omega)+\frac{\mathrm{Z}_{\mathrm{L}}(j \omega)}{0}} \approx 0 \\
U_{s f}(j \omega)\left(\omega=\omega_{h}\right) \approx Z_{L}(j \omega) I_{L}(j \omega)+U_{s}(j \omega)
\end{array}\right.
$$

Because the combination of the SF and SAPF has a limited power factor correction capability, an independent three-phase converter was suggested in [16] at the sourceside to regulate DC-link voltage within the unified compensator by an isolated control circuit as shown in Fig. 5.

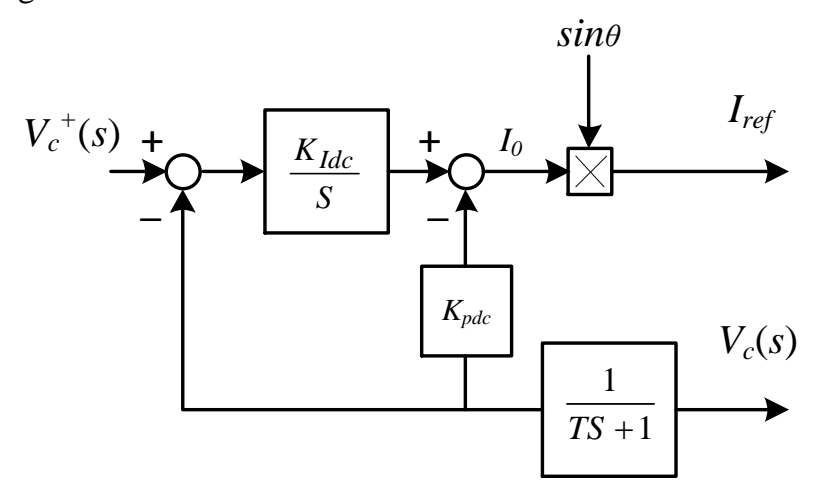

Figure 5: Control diagram of the three-phase rectifier suggested in [16].

The independent DC compensator has the advantage of making the shunt activating algorithm simple, lowering the power density of energy storage elements. Although the independent DC-link compensator at the source-side removes the limitation of power factor correction capability, it imposes distortions and harmonics to the source-end currents.

The aforementioned form of compensator is practically true for three-phase systems as long as load-terminal voltages remain balanced and sinusoidal. Nevertheless, when the power system is unbalanced and distorted in a three-phase/four-wire system, due to the malfunctioning of the compensation algorithm that derived from $\mathrm{d}-\mathrm{q}$ or $\alpha-$ $\beta-0$ theories, the unified compensators introduce unsatisfactory cancelling of the source zero sequence current and harmonics suppression.

\section{Suggesting the AUPQS}

The proposed AUPQS also includes a combination of a shunt active filter, a series active filter and an independent rectifier like that of [16]; but, the AUPQS proposes a single-phase rectifier at the load-end instead of previously raised three-phase rectifier at the source-end. It is shown that shunt active filter, activated by the compensation algorithm based on the A-GTIP theory ([7]), leads to 
satisfactory performance under distorted and unbalanced load-terminal voltages in three-phase four-wire systems. Nonetheless, a full harmonic cancellation cannot be achieved under capacitive load conditions. Hence, the suggested improved series active filter (see Fig. 4) is used as a complementary device for the SAPF that is activated by the A-GTIP theory. For example, the developed SF of the proposed AUPQS produces output voltage that can compensate the wind turbine voltage deficiencies. Meanwhile, in the case of capacitive load, harmonics would flow into the shunt part of the AUPQS. Moreover, the independent single-phase converter at the load-end, unlike the previous proposition of a three-phase converter at the source-end, would be able to regulate the DC-link voltage without imposing distortions and harmonics at the source-end. The reason is that the shunt filter of the AUPQS would absorb distortions generated by the independent single-phase converter. Figure 6 shows the proposed AUPQS.

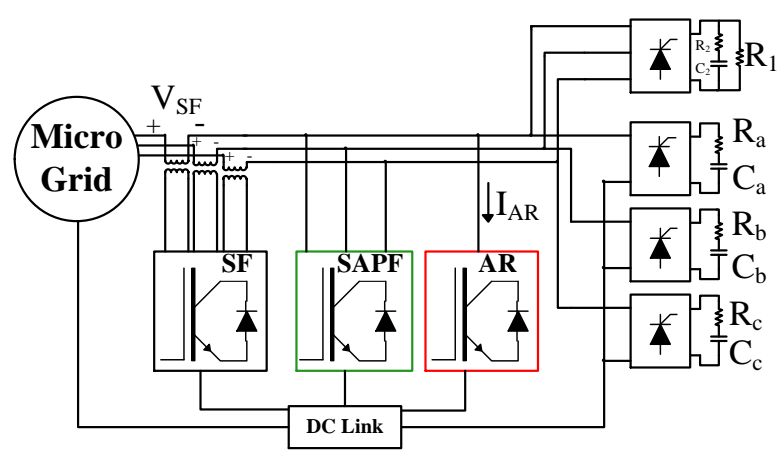

Figure 6: The AUPQS power circuit.

\section{Simulations and discussions}

To verify the flexibility of the AUPQS, a micro-grid was simulated as shown in Fig. 7. The micro-grid consists of a synchronous source (combustion engine / synchronous generator), a wind generator, unbalanced non-linear capacitive load and the compensator (AUPQS). Both the synchronous source and the wind generator contribute to generate the desired maximum power, a power system similar to that introduced in [21]. Also, non-linear loads in Fig. 7 consist of three single-phase rectifiers that supply the circuit elements in Fig. 6. Table 1 introduces the parameters of these loads.

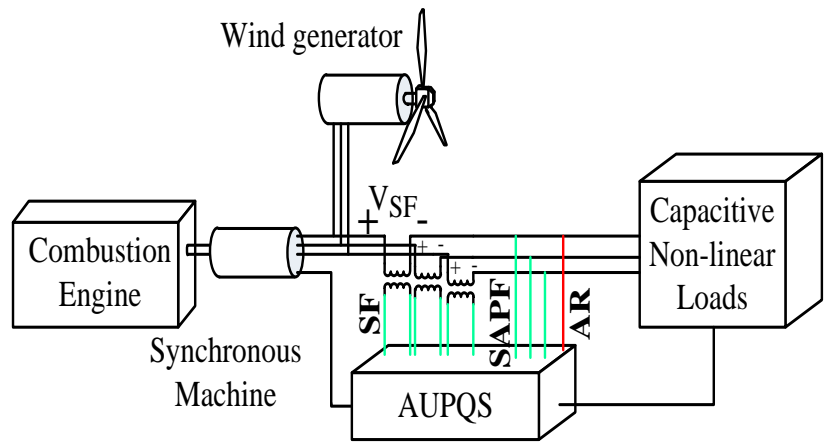

Figure 7: Simulated power circuit of the micro-grid involving four-wire unbalanced and/or capacitive load.
TABLE 1: PARAMETERS OF SINGLE-PHASE AND THREE-PHASE LOADS SHOWN IN FIG. 6.

\begin{tabular}{|l|l|}
\hline$R_{a}=1 / 2[\Omega]$ & $C_{a}=0.5[\mathrm{mF}]$ \\
\hline$R_{b}=1 / 3[\Omega]$ & $C_{b}=50[\mathrm{mF}]$ \\
\hline$R_{c}=1 / 3[\Omega]$ & $C_{c}=5[\mathrm{mF}]$ \\
\hline \multirow{2}{*}{$R_{l}=3 \quad[\Omega]$} & $C_{2}=50[\mathrm{mF}]$ \\
\cline { 2 - 2 } & $R_{2}=0.5[\Omega]$ \\
\hline
\end{tabular}

A passive LCL-filter is used to attenuate the unwanted frequency components resulting from the switching modulation of shunt part of the AUPQS [22]. Parameters of the converter and the LCL-filter are shown in Table 2.

TABLE 2: THE PARAMETERS OF THE SAPF

\begin{tabular}{|l|l|}
\hline SAPF side $L C L$ filter inductance $\mathrm{L}_{1}$ & $4.1[\mathrm{mH}]$ \\
\hline Grid side $L C L$ filter inductance $\mathrm{L}_{2}$ & $0.5[\mathrm{mH}]$ \\
\hline LCL filter capacitor $\mathrm{C}_{\mathrm{f}}$ & $10[\mu \mathrm{H}]$ \\
\hline LCL filter damping resistor $\mathrm{R}_{\mathrm{f}}$ & $20[\Omega]$ \\
\hline SAPF Switching frequency & $6: 9[\mathrm{kHz}]$ \\
\hline SAPF DC-link capacitors (each one) & $2[\mathrm{mF}]$ \\
\hline SAPF DC-link voltage & $700[\mathrm{v}]$ \\
\hline
\end{tabular}

In this simulation a hysteresis current control modulation technique is employed to drive the switches with variable frequencies [23]. Fig.8 shows the load and the source currents after the compensation by proposed A-UPQS in three-phase four-wire system respectively. This simulation shows that current distortions were extremely decreased. Figs.9 and 10 show the real power (p) and imaginary power $(q)$ before and after proposed AUPQS is connected to Micro-Grid respectively. It can be seen that $\tilde{\mathrm{P}}$ and $\mathrm{q}$ are extremely compensated. So, the maximum electrical micro-grid efficiency will be assured.
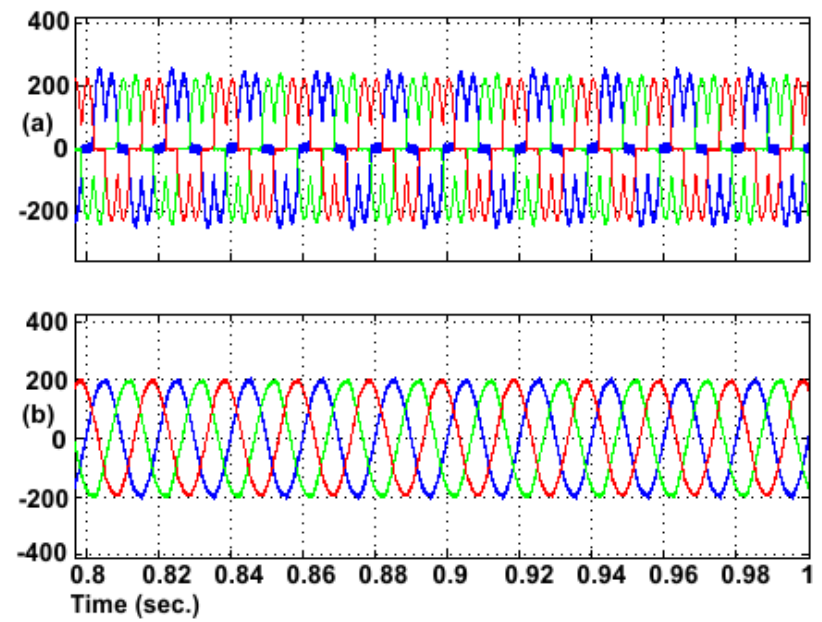

Figure 8: The source-end currents in three-phase/four-wire system, (a) before compensation (A) (THD 23.63\%), (b) after compensation (THD 0.97\%). 


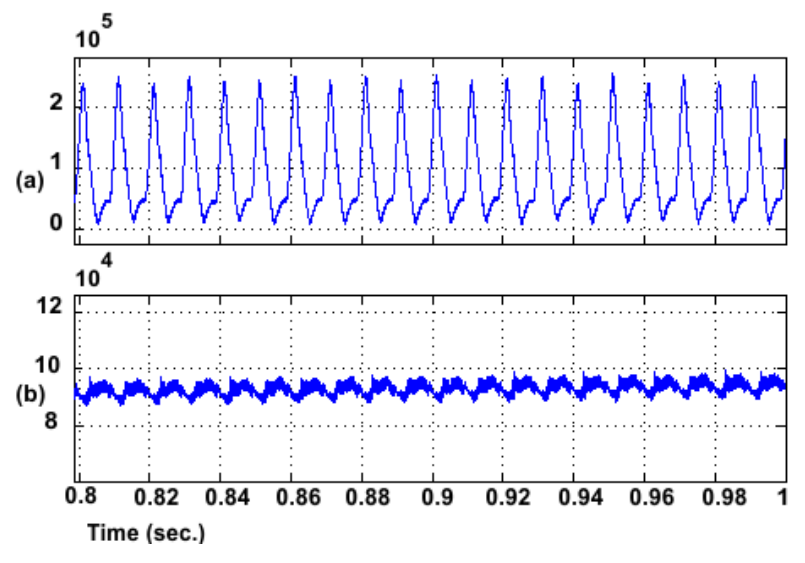

Figure 9: Micro grid real power (W), (a) before compensation, (b) after compensation.

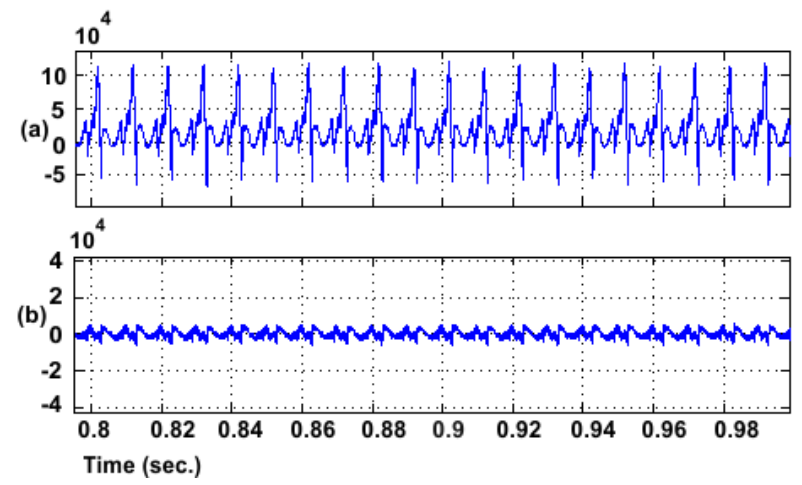

Figure 10: Micro grid imaginary power (Var), (a) before compensation, (b) after Compensation.

\section{Conclusion}

An advanced unified power conditioning system which is able to fully cancel the real and imaginary oscillating powers under any distorted unbalance conditions in micro grids was proposed. This paper showed that not only both $\mathrm{p}-\mathrm{q}$ and $\mathrm{p}-\mathrm{q}-\mathrm{r}$ theories are unable to fully compensate the unbalance components as well as distortions, but also the compensation algorithm based on the new A-GTIP theory for the shunt active filters would not lead to fully compensations especially for the capacitive loads. The proposed A-UPQS used complementary series active filter for eliminating the shunt filter malfunctioning. Further, a singlephase converter connected to the load-side, regulates the DC bus of the A-UPQS. This enables the A-UPQS to suppress the disturbances of previously suggested three-phase converter at the source-end. The proposed A-UPQS was applied to a micro grid. The simulation results showed that the proposed A-UPQS would lead to eliminate unwanted instantaneous powers and alleviate the torsional torque oscillations. Therefore, the efficiency and effectiveness of the micro grids were assured.

\section{References}

[1] D. Sabin and A. Sundaram, "Quality enhances reliability ", IEEE Spectr., vol. 33, no. 2, pp. 34-41, Feb. 1996.

[2] S. Fryze, "Effective wattless and apparent power in electrical circuits for the case of non-sinusoidal waveform of current and voltage", in elektrotechnische zeitschr, 53,pp 596-599, 1932

[3] Leszek S. Czarnecki, "Minimization of Unbalanced and Reactive Currents in Three-Phase asymmetrical Circuits with Non-sinusoidal Voltage", IEE Proceedings-B, 139, No. 4, 347-354, 1992.
[4] F. Z. Peng,and J. S. Lai, "Generalized Instantaneous Reactive Power Theory for Three-phase Power Systems", IEEE 00189456/96\$05.00 01996.

[5] Mohammad Tavakoli Bina, "Inactive Power Harmonics Control", ISBN: 964-94808-4-6, PP 46-50, 2003, (in Farsi).

[6] E. Pashajavid and Mohammad Tavakoli Bina, "Zerosequence component and Harmonic Compensation in fourwire Systems under Non-ideal Waveforms", PRZEGLA¿D ELEKTROTECHNICZNY (Electrical Review), ISSN 0033-2097, R. 85 NR 10/2009.

[7] B. Rahmani and M.Tavakoli Bina, "Eliminating the consequence of Non-Ideal Waveforms on the SAPF Accuracy due to the Wind Turbine operation within a Micro-Grid", annual EWEA conference, 2011.

[8] M. Depenbrock, "The FBD-Method, a Generally Applicable Tool for Analysing Power Relations", IEEE Transactions on Power Systems, vol. 8, no. 2, pp. 381- 387, May 1993.

[9] Leszek S. Czarnecki, "Currents' Physical Components (CPC) In Circuits with Non-sinusoidal Voltages and Currents Part 2: Three-Phase Three-Wire Linear Circuits", Electrical Power Quality and Utalization, Journal, Vol .XI, No2, 2005.

[10] P. Tenti, E. Tedeschi, P. Mattavelli, "Cooperative Operation of Active Power Filters by Instantaneous Complex Power Control", 7th International Conference on Power Electronics and Drive Systems, November 2007.

[11] H. S. Kim, H. Akagi, "The instantaneous power theory on the rotating 694 p-q-r reference frames", in Proc. IEEE/PEDS Conf., Hong Kong, Jul., pp. 422-427, 1999.

[12] M. Depenbrock, V. Staudt, H. Wrede, "Concerning instantaneous power compensation in three-phase systems by using $\mathrm{p}-\mathrm{q}-\mathrm{r}$ theory", IEEE Transactions on Power Electronics, vol. 19, no. 4, pp. 1151-1152, Jul. 2004.

[13] M. Aredes, H. Akagi, E. H. Watanabe, E. V. Salgado, L. F. Encarnação, "Comparisons Between the p-q and p-q-r Theories in Three-Phase Four-Wire Systems", IEEE Transactions on Power Electronics, paper accepted in October 6, 2008

[14] G. O. Suvire, "Mitigation of Problems Produced by Wind Generators in Weak Systems," Ph.D. Thesis, San Juan National University, Argentina, 2009, (in Spanish).

[15] H. Fujita and H. Akagi, "The unified power quality conditioner: the integration of series and shunt-active filters", IEEE Trans. Power Electron. vol.13, no. 2, pp.315322, Mar, 1998.

[16] D. Graovac, V. A. Katic and A. Rufer, "Power quality problems compensation with universal power quality conditioning system", IEEE Trans. Power Del., 2007.

[17] Mohammad Tavakoli Bina, "A New Complementary Method to Instantaneous Inactive Power Compensation", IEEE 0-7803-7754-0/03/\$17.00 02003.

[18] B. Rahmani and M.Tavakoli Bina, "The Compensation Algorithm Based on Advanced GTIP Theory for Switching Compensators and Possibility of the Micro-Grids' Stability", PSC $25^{\text {th }}$ international power system conference, 10-F-PQA-1205, 2010, (in Farsi).

[19] I. Van der Hoven, "Power Spectrum of Horizontal Wind Speed in the Frequency Range from 0.0007 to 900 Cycles per Hour", Journal of Meteorology, vol. 14, pp. 160-164, April 1957. 
[20] T. Goya et al, "Torsional Torque Suppression of Decentralized Generators Based on Hळ Control Theory", International conference on Power System Transient (IPST'2009), Kyoto, 2-6June 2009.

[21] L. F. C. Monteiro, J. L. Afonso, J. G. Pinto, E. H. Watanabe, M. Aredes, and H. Akagi, " Compensation algorithms based on the p-q and CPC theories for switching compensators in micro-grids", IEEE 978-1-4244-3370, 2009.

[22] M. Tavakoli Bina, E. Pashajavid, "An Efficient Procedure to Design Passive LCL-filters for Active Power Filters", Electr.Power Syst. Res., 79, No. 4, pp 606-614, 2009.

[23] J. Holtz, "Pulse width Modulation-A survey", IEEE Trans. On Industrial Elect. (39), No. 5, pp 410-420, 1992. 